\title{
A Study on Cross-Cultural Adaptation of International Students in China from Confucius Institute at the University of Khartoum
}

\author{
Li Zhang1, Mojahid Mohamedahmed Elsadig Mohamedahmed ${ }^{2}$, Feng Xiao ${ }^{3 *}$ \\ ${ }^{1}$ Institute for International Education, Guangdong University of Foreign Studies, Guangzhou, China \\ ${ }^{2}$ Consulate General of the United Arab Emirates, Guangzhou, China \\ ${ }^{3}$ School of Information Science and Technology, Guangdong University of Foreign Studies, Guangzhou, China \\ Email: *xiaofeng@gdufs.edu.cn
}

How to cite this paper: Zhang, L., Mohamedahmed, M. M. E., \& Xiao, F. (2020). A Study on Cross-Cultural Adaptation of International Students in China from Confucius Institute at the University of Khartoum. Creative Education, 11, 2772-2789.

https://doi.org/10.4236/ce.2020.1112203

Received: November 23, 2020

Accepted: December 20, 2020

Published: December 23, 2020

Copyright $\odot 2020$ by author(s) and Scientific Research Publishing Inc. This work is licensed under the Creative Commons Attribution International License (CC BY 4.0).

http://creativecommons.org/licenses/by/4.0/

\begin{abstract}
Since China and Sudan have different cultural backgrounds, international students from Sudan certainly will have trouble in learning. How can they improve their cross-cultural adaptation? By taking the international students in China from Confucius Institute at the University of Khartoum (CIUOFK), and by means of questionnaire survey and interviews, this paper finds that difficulties they have to face in cross-cultural adaptation include living environment, the weather, dietary habits and means of transportation. And then this paper has an in-depth exploration of reasons behind these difficulties from four aspects, i.e. living environment, academic environment, interpersonal communication and mental adaptation. In the end, the author suggests that the students should be eased at both universities and individual levels, and also puts forward some pertinent suggestions in terms of those common difficulties for the students.
\end{abstract}

\section{Keywords}

Sudan, International Students in China, Confucius Institute, University of Khartoum, Cross-Cultural Adaptation

\section{Introduction}

In recent years, the number of international students in China is rising steadily, and the number of Sudanese students has also increased year by year. According to the data from CIUOFK, 137 students from CIUOFK established by Northwest Normal University (NWNU) have been admitted by major colleges and universities in China and won the Confucius Institutes Scholarships, of which 16 stu- 
dents are accepted by Northwest Normal University. This also allows CIUOFK of NWNU to once again become the Confucius Institute with the largest number of Confucius Institute Scholarships winners in the world after 2017. In recent years, CIUOFK has constantly strengthened its education and teaching capacity building and strived to its teaching methods and means so that its teaching quality and level has been steadily improved and it has also cultivated a group of outstanding students to study and exchange in China.

In 1960, Oberg raised a concept of "cultural shock", meaning the cultural inadaptation a person encountered from one environment to another environment. For Sudanese students studying in China, differences in customs, values and language culture will make them feel uncomfortable, and serious situations even may cause such cultural conflicts as interpersonal conflict and inadaptation to learning environment. In this Paper, a survey is made for Sudanese students from many colleges and universities in China to discuss their social and cultural adaptation, mental adaptation and any other factors and research effects of cultural conflict on their study in China including study and lives, further giving advice to help them better adapt to China's culture.

The researches in the filed of cross-cultural adaptation are fruitful up to now, but most focus on the research of Western scholars. Previous studies have mostly concentrated upon the adaptation problems of students from developing countries to study in developed countries, but there is a lack of cross-cultural adaptation studies for international students in China. After 2000, as the number of foreign students studying in China has been increasing constantly, researches in this field are also increasing accordingly. Meanwhile, still few researches on African countries have been conducted. Therefore, this Paper takes Sudanese students as its research object, probes into their problems in living environment, mental state and study and also gives specific advice, hoping to provide a reference for Sudanese students to better adapt to Chinese culture.

\section{Research Background}

The concept of cultural adaptation was first put forward in 1936 by American anthropologist Robert Redfield and others. Since the beginning of the last century, the phenomenon of cross-cultural adaptation has attracted attention in western countries, especially on the issue of immigration. Then the attention was turned to international students' cultural adaptation, and abundant research results were accumulated in this aspect. John. Schumann's cultural adaptation theory was proposed to explore the rule of foreign language learning from two aspects including social environment factor and learners' personal psychological factor and overcome disadvantages affecting foreign language learners during their study. Berry discussed in detail the connotation of cultural adaptation, modes of cultural adaptation theories and enlightenment to national education. In 1960, Oberg raised the concept of culture shock, that is, inadaptation to environment in a new culture. Representative studies on international students' emotional adaptation changes from time dimension are listed as Table 1: 
Table 1. Major representative scholars of cross-cultural adaptation and their views.

\begin{tabular}{|c|c|}
\hline Scholars & Views \\
\hline Lysgaard & $\begin{array}{l}\text { U-shaped curve hypothesis: it pointed out that the cross-cultural mental state of } \\
\text { international students presents a U-shaped curve. That is to say, the mental state of } \\
\text { students who have stayed in the US for } 6 \text { - } 18 \text { months is worse than that of those } \\
\text { who have stayed in the US for less than } 6 \text { months or more than } 18 \text { months. }\end{array}$ \\
\hline Oberg, 1960 & Four-stage theory: stages of honeymoon, crisis, recovery and adaptation. \\
\hline Ward, 1998 & $\begin{array}{l}\text { From four time points measurement of Japanese students in New Zealand, it was } \\
\text { observed that their depression disorder is worst when they first come to New } \\
\text { Zealand. While in the other three time periods, the changes in depression are not } \\
\text { apparent. The result cannot prove the U-shaped curve hypothesis. }\end{array}$ \\
\hline Ward, 1996 & $\begin{array}{l}\text { From time point measurement of Malaysian and Singaporean students in New } \\
\text { Zealand, it was observed that students' mental changes resemble an inverted } \\
\text { U-shape, that is to say, those who have been in New Zealand for a month or over a } \\
\text { year have the strongest mental shift. }\end{array}$ \\
\hline Gullahorn, 1963 & $\begin{array}{l}\text { W-curve: honeymoon period; struggle period; dispute period; adaptation period; } \\
\text { re-dispute period-still uncertain of some complicated problems; early period } \\
\text { before returning-looking forward to returning with joy; shock after returning-a } \\
\text { feeling of estrangement when contacting with people and in daily life. }\end{array}$ \\
\hline
\end{tabular}

Related researches in China mainly include:

Some scholars have discussed the cross-cultural adaptation of international students from different regions and countries (Fan \& Hu, 2010; Xing, 2013; Anokin, 2016; El-Said Abbas Ibrahim, 2017; Lin, 2018). Some scholars have also conducted a survey on international students from a certain university. For instance, $\mathrm{Xu}$ and $\mathrm{Hu}$ (2017) have analyzed and discussed the motivation of studying abroad, eating habits and social interact by adopting the questionnaire method and taking the undergraduate international students from Nanchang Hangkong University as their respondents. They believe that international students should have a better understanding of Chinese culture and customs, and also emphasize that schools should organize activities that enable international students to understand and adapt to Chinese culture. Pu, Zhang and Peng (2013) have investigated the cross-cultural adaptability of international students from Northwest University, finding that the language barriers cause problems of interacting with other people. Ji (2011) has studied 14 Ukrainian students in China, expounded cultural differences between China and Ukraine from the perspectives of face-saving value, sense of time and means of expression and further proposed teaching strategies. They are of the opinion that great importance should be attached to cultivate multiple culture consciousness and take the initiative to learn about Chinese culture.

Some scholars also put forward detailed suggestions. Zhang and Chen (2013) have proposed countermeasures from two aspects. First is from the level of schools. Colleges and universities should encourage students to participate in club activities and arrange training courses to let them understand Chinese culture. Second is from the international students level. They should make clear their goal of studying in China and respect Chinese law. Wang (2010) has summarized 35 ways of acculturation commonly used by international students in 
China. Researches of Xue (2014) indicate that, during the crisis stage and initial adaptation stage of $\mathrm{U}$-curve and $\mathrm{W}$-curve, cross-cultural adaptation guidance and social support are quite important for international students. Shi (2014) deems that cross-cultural adaptation should be positively associated with participation in local social and cultural life and acquisition of social support.

\section{Surveys and Researches}

\subsection{Overall Design of Questionnaire}

Questionnaires the author designed are oriented to the international students in China from CIO. And a questionnaire is divided into four parts as below: living environment adaptation, academic environment adaptation, interpersonal communication and mental adaptation. This survey has collected 74 effective questionnaires.

\subsection{Basic Information of Survey Respondents}

\subsubsection{Gender}

The survey respondents include 50 males and 24 females, of which the number of males is the double of that of females. This is because Sudanese society is conservative and conventional, most girls get married at the age of 23 or so, and most parents are unwilling to allow their daughters to study abroad alone.

\subsubsection{Age}

Among the respondents under survey, there are 2 students under 18, 36 students between 18 and 25, 35 students between 26 - 35 and only 1 student above 35, of which the respondents between 18 and 35 account for the largest number. This means most students come to China as soon as they graduate from high schools or universities.

\subsubsection{Student Type}

From Table 2, we can see that the number of undergraduates and postgraduates is the largest, as these two kinds of students have more opportunities to gain scholarships. The other types of students are mostly short-term advanced students who study various majors in China's colleges and universities. Among these majors, Chinese (Language), Teaching Chinese to Speakers of Other Languages (TCSOL) and Engineering rank the top three. A few students have chosen Medicine, Translation and Interpreting, International Logistics and International Relations.

\subsubsection{Duration of study in China}

For the students under survey, the time they've spent in China also differs. 22 students have been in China for less than 2 years, 25 students for 3 - 5 years, 21 students for 5 - 8 years, and 6 students for over 8 years. Among them, undergraduates account for the largest number, and doctors or post doctors account for the least number. 


\subsubsection{Proficiency in Chinese}

From Table 3, we can see that about 65\% students have passed the exam of HSK Level V or above, which show that Sudanese international students have proficiency in Chinese. Although they've learnt basic Chinese in Sudan, most of their teachers are Chinese people, and they also have a hanger for knowledge. Hence, they have a solid foundation of Chinese.

\subsection{Content of Survey}

\subsubsection{Living Environment Adaptation}

Gudykunst \& Kim (2007) believes that the living environment adaptation problem comes first in the cultural adaptation. Such climate changes caused by different geographical locations and differences in food culture, schools' accommodation management systems and public service systems have affected the cross-cultural adaptability of international students in China to some different extent.

\subsubsection{Learning Environment Adaptation}

Sudanese students attach much importance to their study and school management and they expect to study in schools which meet their requirements like many other foreign students. Many foreign students complain that their specialized courses are boring but they face high pressure and are assigned much homework at the same time. All these factors will have an influence on their academic performance. Sudanese students are more dependent on teachers, and only through the guidance of teachers can they make progress. However, they find that the situation in China is different. Chinese teachers only give students general guidance to students, and students' study mostly rely on their own efforts. This may also affect Sudanese students' attitude toward study.

Table 2. Table of student type distribution.

\begin{tabular}{ccc}
\hline Educational Background & Number & Proportion \\
\hline Undergraduate & 34 & $45.95 \%$ \\
Postgraduate & 24 & $32.43 \%$ \\
Doctoral & 10 & $13.51 \%$ \\
Others & 6 & $8.11 \%$ \\
\hline
\end{tabular}

Table 3. Distribution table of the respondents' proficiency in Chinese.

\begin{tabular}{ccc}
\hline proficiency in Chinese & Number & Proportion \\
\hline Level II & 8 & $10.81 \%$ \\
Level III & 4 & $5.41 \%$ \\
Level IV & 14 & $18.92 \%$ \\
Level V & 23 & $31.08 \%$ \\
Level VI & 25 & $33.78 \%$
\end{tabular}




\subsubsection{Interpersonal Communication Adaptation}

During international students' life of studying in abroad, it is inevitable to have cross-cultural communication with people of different cultural backgrounds. They are faced with a new cultural background completely different from their own country after they come to China. They will certainly run into cross-cultural communication problems as well as cross-cultural communication barriers.

Sudanese students in China study in different cities. Most of them are in the in the north, especially in Gansu Province with the largest number that is mainly concentrated in NWNU and Lanzhou University. Instead, few Sudanese students choose to study in southern China. Each part of China has its own dialects such as Hakka language, Cantonese and Southern Fujian Dialect. These dialects may exert negative influences on Sudanese students' Chinese learning and make their Chinese slipping.

\subsubsection{Mental Adaptation}

Some foreign students will feel uneasy, anxious and even become wakeful after they first come to a new country. The mental adaptability of international students in China has a lot to do with the length of their stay in China: those who have been in China for a short time have relatively more depressive symptoms. The international students in China mainly have such psychological barriers as loneliness, self-imposed isolation, impatience, irritability, anxiety and depression, and they are prone to adopt negative reactions including fantasy and evasion in the face of stress events. Many Sudanese students in China have mental problems such as anxiety and restlessness during their early days in China, but they become accustomed to their lives in China as they stay here for a long time. Therefore, those Sudanese students who have lived in China for over 4 years have totally adapted to lives in China.

\section{Analysis of Influencing Factors}

\subsection{Influencing Factors of Living Environment Adaptation}

\subsubsection{Living Habits}

Sudanese students have different opinions on the life in China. Some are fairly satisfied with their life in China, some are not quite satisfied and some others are not still not sure. Sudanese students who have just come to China are not quite comfortable with China's living habits, and the influencing factors main include local climate, eating habits and social interaction, etc.

From Table 4, over half of Sudanese students are not pleased with new environment, and feel hard to adapt to the life of cities where they are because of language barrier after they come to China. In an unfamiliar environment, they often feel lonely and lost because they have no relatives and friends around, so they will also feel a sense of anxiety.

\subsubsection{Dietary Habits}

Food has always been the biggest difficulty that international students have faced. Most Sudanese students have a belief in Islam, so they only eat halal food. 
They call speeches, behaviors and food conforming to Islam law as "HALAL" and those that don't conform to as "HARAM".

Muslim food culture has two important features: legitimacy and pleasance. Legitimacy here has two meanings. The first is that food must be permitted by the Koran and are made as stipulated by the Islam law. The second is that food should also conform to social public law. Pleasance here means that each step for food making from procurement of raw materials to serving to the table should be clean, healthy, pollution free and nonhazardous.

As a result, the biggest problem that Sudanese students in China face is to find halal food. The staple food of Sudan is Arabic flatbread and bread. They like to eat hand pilaf and can only eat halal meat. They are used to eating with their right hand and are prohibited drinking all kinds of drinks. These eating habits are strikingly different from ones in China. Table 5 and Table 6 show their viewpoints on Chinese food.

Table 4. Ecological environment of the city where you live is favorable.

\begin{tabular}{lll}
\hline Options & Number & Proportion \\
\hline a Totally agree & 15 & $20.27 \%$ \\
b Agree & 4 & $5.41 \%$ \\
c Not sure & 14 & $18.92 \%$ \\
d Disagree & 23 & $31.08 \%$ \\
e Totally disagree & 18 & $24.32 \%$ \\
\hline
\end{tabular}

Table 5. You get used to Chinese dishes.

\begin{tabular}{lll}
\hline Options & Number & Proportion \\
\hline a Totally degree & 19 & $25.68 \%$ \\
b Agree & 9 & $12.16 \%$ \\
c Not sure & 19 & $25.68 \%$ \\
d Disagree & 12 & $16.22 \%$ \\
e Totally disagree & 15 & $20.27 \%$ \\
\hline
\end{tabular}

Table 6. How does halal food in your city taste?

\begin{tabular}{lll}
\hline Options & Number & Proportion \\
\hline a. Very tasty & 21 & $28.38 \%$ \\
b. Relatively tasty & 22 & $29.73 \%$ \\
c. General & 22 & $29.73 \%$ \\
d. Not tasty & 5 & $6.76 \%$ \\
e. Awfully unsavory & 4 & $5.41 \%$
\end{tabular}


Due to the huge difference in eating habits, many Sudanese students cannot get used to Chinese food and often have stomachaches. Table 6 illustrates Sudanese students like eating halal food and they generally eat meals in restaurants for Lanzhou stretched noodles or other Arabic restaurants. But there are also some students consider that the halal food in China are not to their liking. In the survey, 9 students feel the halal food tastes bad.

\subsubsection{Climate}

The climate in Sudan differs in each part. The arid desert has high temperatures sometimes up to $50^{\circ} \mathrm{C}$ and it has an average annual temperature of $21^{\circ} \mathrm{C}$. Cities in northern China are cold and dry, while coastal cities in the south are warmer and humid. Thus most Sudanese students can adapt to the climate in the cities where they live, and some students have weak adaptabilities. The three international students the author interviews from Beijing Language and Culture University and NWNU consider that the climate in their cities is much cold so that they are likely to get cold and ill. Table 7 reveals the respondents' evaluation on climate and that $47 \%$ Sudanese students cannot adapt to the climate of their cities.

\subsubsection{Means of Transportation}

As shown in Table 8, 45.95\% students are very dissatisfied with transportation in China, indicating that almost half the students hold that it is inconvenient to travel. $25.68 \%$ of them deem that the transportation in China is convenient. That is because the cities where they are have small population density, the frequency of using transportation is not high, and traffic jams rarely occur. But in big cities, there is a high population density and a high travel demand, so traffic jams occur frequently. Especially in certain periods, transportation is very inconvenient. For example, during rush hours on working days, it is inevitable to be crowded by bus, subway or taxi. And during such traditional festivals as the Spring Festival, the Mid-Autumn Festival and the National Day, it is extremely hard to buy a high-speed rail ticket. Many people had to choose a slower way like long-distance buses as they cannot scramble for the tickets.

\subsection{Influencing Factors in Learning Environment Adaptation}

\subsubsection{Campus Environment Factor}

Sudan's schools are very different from Chinese schools. Although each school has dormitories, the public facilities are not so good. Sudanese students pay more attention to campus environment after coming to China. Table 9 represents their opinions, i.e. nearly half the students are dissatisfied with the campus environment of their schools. According to a further investigation, it is found that they are mainly not satisfied with the conditions of their dormitories.

\subsubsection{Class Adaptation Factor}

Sudanese students are very dependent on teachers and they need the guidance of teachers when doing everything. Each time an activity is held, they will need 
their mentors, or they will not rehearse on their own. Sudanese student generally don't like too much homework, and homework has been always one of their troubles. However, homework is very common for Chinese students.

From Table 10, it can be seen that Sudanese students in China don't feel liking going out. Over half of them prefer to stay in the dormitories, and they neither go out to amuse themselves nor work outside. Based on the author's further understanding, many Sudanese students feel that they have high pressure and much homework, so they opt to stay in dormitories for learning.

Table 7. You adapt to local climate well.

\begin{tabular}{lll}
\hline Options & Number & Proportion \\
\hline a Totally agree & 17 & $22.97 \%$ \\
b Agree & 12 & $16.22 \%$ \\
c Not sure & 10 & $13.51 \%$ \\
d Disagree & 18 & $24.32 \%$ \\
e Totally disagree & 17 & $22.97 \%$ \\
\hline
\end{tabular}

Table 8. You think transportation in China is very convenient.

\begin{tabular}{llc}
\hline Options & Number & Proportion \\
\hline a Totally agree & 19 & $25.68 \%$ \\
b Agree & 2 & $2.70 \%$ \\
c Not sure & 3 & $4.05 \%$ \\
d Disagree & 16 & $21.62 \%$ \\
e Totally disagree & 34 & $45.95 \%$ \\
\hline
\end{tabular}

Table 9. Campus environment of your school is beautiful.

\begin{tabular}{lll}
\hline Options & Number & Proportion \\
\hline a Totally agree & 14 & $18.92 \%$ \\
b Agree & 8 & $10.81 \%$ \\
c Not sure & 4 & $5.41 \%$ \\
d Disagree & 29 & $39.19 \%$ \\
e Totally disagree & 19 & $25.68 \%$ \\
\hline
\end{tabular}

Table 10. What do you like to do in your spare time?

\begin{tabular}{lll}
\hline Options & Number & Proportion \\
\hline a. Stay in dormitories & 39 & $52.70 \%$ \\
b. Visit local places of interest & 12 & $16.22 \%$ \\
c. Do some part-time jobs & 13 & $17.57 \%$ \\
d. Others & 10 & $13.51 \%$ \\
\hline
\end{tabular}




\subsubsection{Teaching Quality Factor}

FFrom Table 11, it can be seen that more than half of Sudanese students are satisfied with the teaching quality of their schools. But they feel stressed out after coming to China and deem that Chinese is very difficult in listening, speaking, reading and writing. This is mainly because Sudanese students are heavily dependent on their teachers. Before studying in China, they lack initiative and motivation in learning and depend much on their teachers. However, teaching methods in China are a bit different, and teachers expect students to do by themselves and give them more space in learning. Therefore, Sudanese students will feel and stressed after coming to China.

\subsubsection{Management of International Students}

In recent years, the number of foreign students has increased year by year, and the demand for related services has increased as well. But related service management agencies and personnel have not increased accordingly. Most international students feel discontented with management systems of colleges and universities. From Table 12, it can be seen that over half of Sudanese students think that school management systems in China are very rigid. For instance, too many absences will affect their exam and the students may be even expelled from school. Besides, students are not allowed to return late to dormitories that will close after 11 o'clock. Though these regulations are stipulated for safety of international students, some of them will regard them as a restriction of personal freedom and cannot understand. On the contrary, some schools are not strict enough to manage international students in China, so it becomes common for many international students to be late for or absent from classes. It is known that China has no speciality as international students management, and administrative staff for internal students management are currently trained discontinuously. So there is a lack of professional management talents.

Table 11. Teaching quality of your school is high.

\begin{tabular}{lll}
\hline Options & Number & Proportion \\
\hline a Totally agree & 19 & $25.68 \%$ \\
b Agree & 23 & $31.08 \%$ \\
c Not sure & 11 & $14.86 \%$ \\
d Disagree & 6 & $8.11 \%$ \\
e Totally disagree & 15 & 20.27 \\
\hline
\end{tabular}

Table 12. Your school attaches great importance to management of international students and sets strict requirements.

\begin{tabular}{lll}
\hline Options & Number & Proportion \\
\hline a Totally agree & 12 & $16.22 \%$ \\
b Agree & 28 & $37.84 \%$ \\
c Not sure & 14 & $18.92 \%$ \\
d Disagree & 11 & $14.86 \%$ \\
e Totally disagree & 9 & $12.16 \%$ \\
\hline
\end{tabular}




\subsection{Influencing Factor in Interpersonal Communication Adaptation}

The difficulty of making friends for Sudanese students is proportion to the time they've spent in China. Those who have come to China for a long time are much more willing to join the circle of Chinese friends. In addition, men students are more likely to make friends from the perspective of gender distribution.

From Table 13, it can be seen that Sudanese students contact more with foreign students, and the number of students who interact with Chinese students is also large. However, they seldom associate with their natives since they reckon that it is beneficial to learn Chinese. Therefore, a harmonious relationship between Sudanese students and the locals contributes to their cross-cultural adaptation in China.

\subsubsection{Communicative Culture Difference}

The international students are curious about China before coming to China. But there will be also a cultural shock and physical and mental inadaptation in a new environment as values and ideas inherent in their own parent environment will have a certain impact on them. This causes that the international students will opt to avoid or neglect when coming across different cultures. For Sudanese students, cultural difference has affected their lives in China. Their understanding of the new culture is limited to the cognitive level, and there will be many unpredictable situations in real life.

From Table 14, it can be seen that most of Sudanese students adopt a positive attitude to deal with cultural conflicts. The Chinese cultural education they've received in Sudan are entirely divergent from the real life. The cultural knowledge they've learned from classes is relatively basic and shallow, but the cultural connotation in real life needs to be continuously explored and felt.

Table 13. Who do you associate with more in your spare time?

\begin{tabular}{lll}
\hline Options & Number & Proportion \\
\hline a. Chinese students & 25 & $33.78 \%$ \\
b. Foreign students & 35 & $47.30 \%$ \\
c. Sudanese students & 14 & 18.92 \\
\hline
\end{tabular}

Table 14. What will you usually do when running into displeasure caused by cultural difference?

\begin{tabular}{|c|c|c|}
\hline Options & Number & Proportion \\
\hline a. Face it in a positive attitude & 43 & $58.11 \%$ \\
\hline b. Want to go back right away and give up study in China & 6 & $8.11 \%$ \\
\hline c. Talk with your family or friends & 24 & $32.43 \%$ \\
\hline d. Others & 1 & $1.35 \%$ \\
\hline
\end{tabular}




\subsubsection{Personal Characters}

Due to personality, age, adaptability and other factors, it will be difficult for foreign students to have interpersonal communication. The students who are outgoing and open-minded have more opportunities, while those who are introverted and reticent will have less opportunities. From Table 15, it can be seen that the biggest problem Sudanese students confront after coming to China is interpersonal communication barrier. According to the author's findings, most Sudanese students under 20 are introverted and unwilling to go out and take part in activities. They also don't feel like actively contacting with others. With the addition of limited Chinese proficiency, the difficulties in this area are even greater.

\subsection{Influencing Factor in Mental Adaptation}

Mental adaptation refers to personal adaptability in cognition, emotion, attitude and mental health when one is in a new environment. Many international students have lived in their native language for a long time, and some of their experiences have left a deep mark in their hearts and cannot be changed. In a new environment, both values and way of thinking will produce a certain shock to them as well as psychological impact.

\subsubsection{Gender}

Sudan is a relatively conservative nation, and Islam provides that men and women should keep a certain distance. Many students will observe China's customs, especially for boys. Men students will have more chances to make friends and go out. Women students are not. They have to wear headscarves when going out, and their relationship with classmates is normal as Islam stipulates that men and women can only be together in a legal relationship. As a result, Sudanese girls are more conservative than Sudanese boys whose parents are not against their studying abroad.

\subsubsection{Age Factor}

The older international students who come to study in China, the stronger their psychological adaptability, while the younger they are, the weaker their psychological adaptability. The survey reveals that, most of Sudanese students in China are young people who come to China after graduating from high school. There are no older students. The author has interviewed 3 Sudanese students under 20 from South China University of Technology. They often think of their families and friends, and sometimes suffer from insomnia at night. Sometimes they will want to go home. This shows that international students' adaptability has a lot to do with their age.

\subsubsection{Motivation of Learning}

Table 16 explains that most Sudanese students learn Chinese for job demand, and their motivations for learning Chinese are clear. Since China and Sudan communicate with each other in trade more frequently, learning Chinese is 
Table 15. What is the biggest problem you've encountered in China?

\begin{tabular}{lll}
\hline Options & Number & Proportion \\
\hline a. Living environment inadaptation & 25 & $33.78 \%$ \\
b. Learning environment inadaptation & 13 & $17.57 \%$ \\
c. Interpersonal communication barrier & 26 & $35.14 \%$ \\
d. Others & 10 & $13.51 \%$ \\
\hline
\end{tabular}

Table 16. Why do you learn Chinese?

\begin{tabular}{lll}
\hline Options & Number & Proportion \\
\hline a. Job demand & 41 & $55.41 \%$ \\
b. Parents' requirements & 8 & $10.81 \%$ \\
c. Love for Chinese culture & 18 & $24.32 \%$ \\
Others & 7 & $9.46 \%$ \\
\hline
\end{tabular}

conducive to both employment and business startups in the future. At present, many Chinese enterprises invest in Sudan, mainly in the oil and agricultural fields. Therefore, Sudanese students learn Chinese mainly for the purpose of a better job selection in the future.

\subsubsection{Time Factor}

As they stay longer in China, the international students will become more informed of surroundings. The cross-cultural adaptability of international students who have been in China for 3 to 4 years has been remarkably improved than that of students who have been in China for 1 to 2 years. Their mental adaptability will be influenced by how long they stay in China. The Sudanese students who have just come to China will feel anxious, scared, and miss their families, while those who have been in China for a long time have adapted to the living environment of the cities where they live, so their anxiety will also decrease accordingly. International students will have few difficulty in adapting to other cultures if they stay in China for a long time. Therefore, all the schools should organize rich and colorful culture experience activities for the new comers from foreign countries so as to help them enhance their mental adaptability.

\section{Persuasion Principles and Countermeasures for Cultural Adaptability of Sudanese Students in China}

\subsection{Principles of Persuasion}

Principles of persuasion require teachers to be patient and persuasive when educating students and start with raising students' awareness, mobilize students' initiative to make them positive. Principles of persuasion have two aspects included. One is to find out the root of problems, and the other is to give guidance to them so as to help them form good habits. These two aspects complement each other, and neglecting neither of them will achieve the purpose of our education. 


\subsubsection{Principle of Respect}

When going to a new country, foreign students should be strict with themselves and respect the laws and regulations of that country. They must also observe the principle of respect and respect their teachers and schoolmates in classes to build favorable teacher-student relationship. Moreover, the international students should also respect China's etiquette and traditional festivals including the Spring Festival, Qingming Festival and the Dragon Boat Festival as well as customs of each festival.

\subsubsection{Principle of Understanding}

The principle of understanding is an indispensable one for international students in life and they also have to follow this principle. China has a vast land and abundant resources and a profound culture, and also each place has its own unique customs and habits, so the international students need to keep to the principle of understanding in both class and real life and improve their own quality.

\subsection{Countermeasures for Persuasion}

In order to improve the cross-cultural adaptability of international students in China, relevant training should be given to them before they come to China. Thus their adaptability will be strengthened, and then they can be able to better solve the problem of cross-cultural adaptation after coming to China.

\subsubsection{On the Level of Colleges and Universities}

Many Sudanese students have affirmed the efforts their schools have made. For instance, there are no classes scheduled on Friday afternoon so that Muslim students worship on that day without affecting their studies; schools help new freshmen with troubles in eating, shelter and means of transportation; schools also hold culture week activities to invite the students to display their own cultures so that those from different countries can better understand their own customs.

In addition, colleges and universities can also implement some other specific measures: hold cross-cultural activities or set up relevant courses for new international students; organize exchange activities between Chinese students and foreign students to help foreign students enhance their interpersonal communication capability; add language tutoring courses for freshmen and regularly offer some cultural tutoring classes to help them build up confidence and increase interest. Cultural tutoring courses is beneficial to have a deep understanding of Chinese culture, cultivate international students' communicative ability, and decrease misunderstanding and obstacles brough about because of cultural difference.

\subsubsection{On an Individual Level}

On an individual level, foreign students should develop favorable learning and living habits in their daily life, and work out some short-term, medium-term and long-term learning goals to realize them. They also have to improve their will- 
power, overcome difficulties and promote their own quality. Many Sudanese students have not accepted any training on cross-cultural adaptation before coming to China, so their psychological adaptability is weak. Therefore, foreign students had better read some works and textbooks on cross culture and watch some relevant videos before coming to China, which will contribute to improving their cross-cultural adaptability.

\section{Conflicts of Interest}

The authors declare no conflicts of interest regarding the publication of this paper.

\section{References}

Anokin (2016). A Study on Living and Learning Adaptation of Mongolian Students in China. Master's Thesis, Guangzhou: Guangdong University of Foreign Studies.

El-Said Abbas Ibrahim, S. A. (2017). A Study on Cross-Cultural Adaptation of Arabic Students in China. Master's Thesis, Baoding: Hebei University.

Fan, Z. K., \& Hu, J. M. (2010). Cultural Conflicts and Adaptation of Central Asian Students in China. Journal of Xinjiang Normal University (Philosophy and Social Science Version), No. 3, 107-114.

Ji, N. (2011). Cross-Cultural Conflicts between China and Ukraine and Adaptation Strategies in the Perspective of Ukrainian Students in China. Master's Thesis, Nanjing: Nanjing Normal University.

Lin, L. (2018). An Empirical Study on Cross-Cultural Adaptation of African Students in China-Taking Jiamusi University as an Example. Economist, No. 2, 89-91.

Pu, Y., Zhang, W. T., \& Peng, H. (2013). A Survey on Cross-Cultural Adaptation of International Students in China and Related Proposals-Taking Northwestern Polytechnical University as a Case. Journal of Northwestern Polytechnical University, No. 1, 107-112+116.

Shi, J. W. (2014). A Survey on Foreign Students' Cross-Cultural Adaptation-Taking Zhejiang University of Science and Technology as a Case. Journal of Zhejiang University of Science and Technology, No. 2, 114-120.

Wang, R. (2010). A Study on Ways of Acculturation of Foreign Students in China-A Case Survey Based on University of International Business and Economics. Master's Thesis, Beijing: Beijing Normal University.

Xing, Y. (2013). A Survey on Cross-Cultural Adaptation of Foreign Students in China. Journal of Qinghai Normal University, No. 4, 46-49.

Xu, X. Q., \& Hu, N. (2017). A Research on Acculturation of Foreign Students in China-Taking International Students from Nanchang Hangkong University as an Example. Education Research Monthly, No. 12, 64-72.

Xue, H. J. (2014). A Research on Cross-Cultural Adaptation of Foreign Students Receiving Academic Education in China in the Perspective of Social Experiences. Education Research Monthly, No. 11, 75-81.

Zhang, S. L., \& Chen, S. (2013). A Research on Cross-Cultural Adaptation of Foreign Students in China. Overseas English, No. 20, 163-164. 


\section{Appendix}

Questionnaire

Part A

Basic information
A) Your gender $\square$ Male $\square$ Female
B) You have been in China for years
C) You're
Undergraduate 2. Postgraduate 3. Doctor 4. Others
D) You've passed HSK level ?
$\begin{array}{lllll}2 & 2.3 & 3.4 & 4.5 & 5.6\end{array}$
E) Which university are you studying at?

Your major is

Your age: under 18 2. 18 - 25 3. 26 - 35 4. Above 35

\section{Part B}

I) The following are opinions about life, learning, social culture and mental attitude. Please choose your best fit and check “ $\sqrt{ }$ ”. You can only choose one answer.

a) Totally disagree b) Disagree c) Not sure d) Agree e) Totally agree

1) You have known much about China before coming to China?
a
b
c
d
e

2) Do you get used to eat Chinese dishes after coming to China?
a
b
c
d e

3) Ecological environment of the city where you live is favorable?
a
b
c
d
e

4) You're comfortable with local climate?

a $\quad$ b $\quad c \quad c \quad c c$

5) You find China's transport very convenient?

a $\quad b \quad c \quad c \quad d \quad d$

6) Campus environment of your school is beautiful?

a b $\quad c \quad c \quad d \quad r$

7) Teaching quality of your school is high?
b c
d e

a

8) Your school attaches great importance to management of international students and has made strict requirements for students?
a
b
$c$
d e

9) Acquainting Chinese friends is much helpful to improve your Chinese proficiency level?
a
b
c
II) Multiple choice questions
1) You're learning Chinese for ?
Job demand
Parents' requirement
Love for Chinese culture

d

$\mathrm{e}$ 
Others

2) How do you feel when you first come to China?

Feel lonely and often miss my family

Easy to get anxious

Reject everything in China

Feel quite excited and be curious about everything

3) The biggest trouble you've encountered in China is:

Living environment adaptation

Learning environment adaptation

Interpersonal communication

Others

4) For you, it is to get used to China's living habits:

Not difficult at all

A bit difficult

Difficult

Very difficult

5) The halal food in your city is:

Very tasty

Relatively tasty

General

Not tasty

Awfully unsavory

6) Accommodation conditions of your school are:

Very comfortable

Relatively comfortable

General

Not comfortable

Very uncomfortable

7) What do you usually do when you come across displeasure caused by cultural difference?

Face it with a positive attitude

Want to go back right away and give up studying in China

Tell your family or friends

Others

8) Will local dialects cause difficulties to your study?

Have no difficulty

Have a few difficulties that can be overcome

Have great difficulties that impede the learning

Very hard and they are the biggest obstacles in the learning

9) What's your understanding of local dialects?

Quite understand

More understanding

General 
Do not understand

Do not quite understand

10) What do you like to do in your spare time?

Stay in the dormitory

Visit local places of interest

Do some part-time jobs

Others

11) Whom do you associate with in your spare time?

Chinese students

Foreign students

Sudanese students

12) What do you think of your study in China as a whole?

Totally agree

Disagree

General

Totally disagree

Part C

Do you have any other problems about cross-cultural adaptation?

Can you give your school some suggestions to help Sudanese students to better adapt to their lives in China? 